\title{
Correction to: Influence of crustal lithology and the thermal state on microseismicity in the Wakayama region, southern Honshu, Japan
}

Sumire Maeda ${ }^{{ }^{*}}\left(\mathbb{0}\right.$, Shinji Toda ${ }^{2}$, Toru Matsuzawa ${ }^{3}$, Makoto Otsubo ${ }^{4}$ and Takumi Matsumoto ${ }^{1}$

\section{Correction to: Earth Planets and Space (2021) 73:173} https://doi.org/10.1186/s40623-021-01503-3

Following publication of the original article (Maeda et al. 2021), it was noticed that the epicenter distribution in Fig. 2 was different from the original one which the authors had submitted.
The correct Fig. 2 has been provided in this Correction.

The original article (Maeda et al. 2021) has been updated.

${ }^{1}$ National Research Institute for Earth Science and Disaster Resilience, 3-1

Tennodai Tsukuba, Ibaraki 305-0006, Japan

Full list of author information is available at the end of the article 


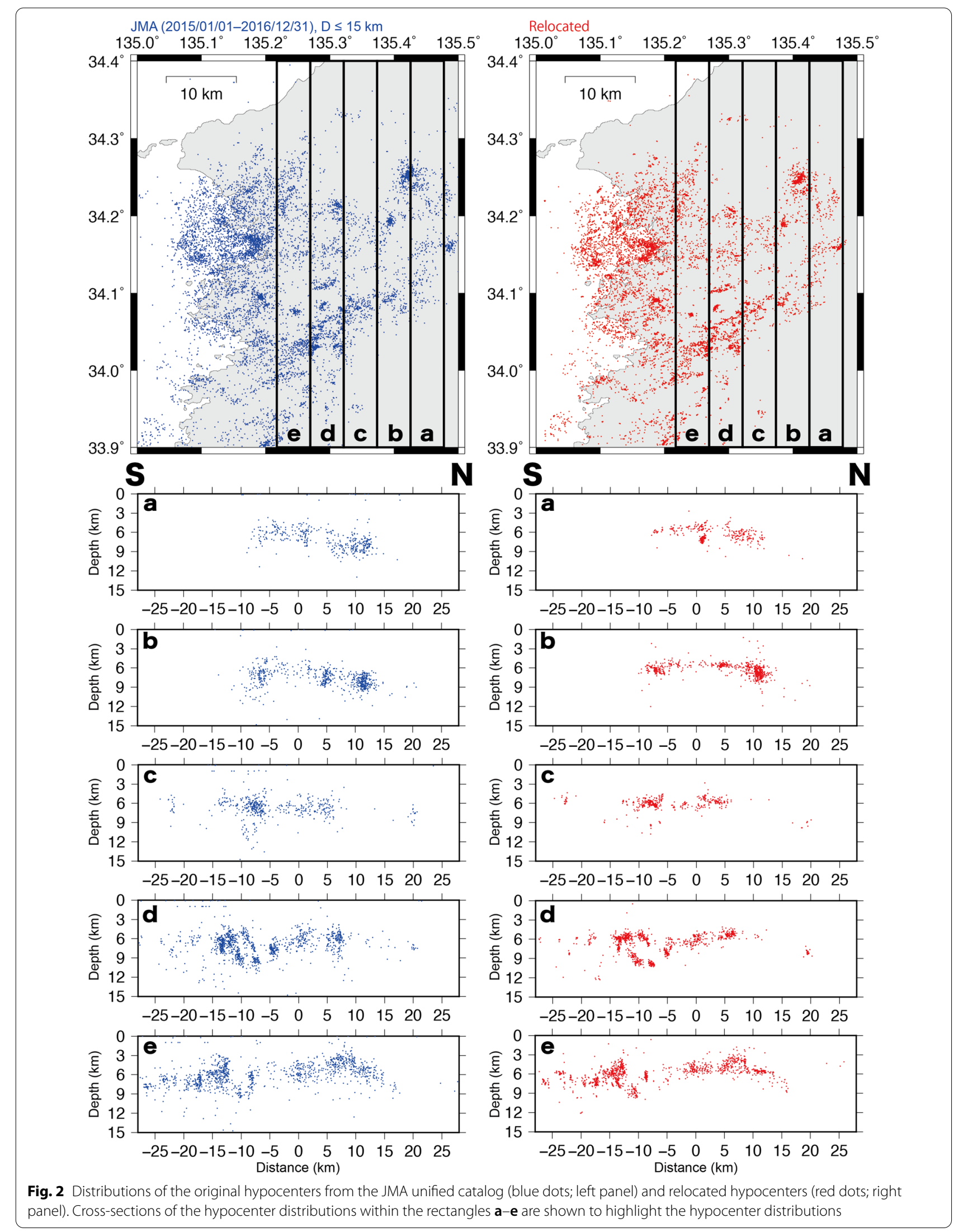




\section{Author details}

National Research Institute for Earth Science and Disaster Resilience, 3-1

Tennodai Tsukuba, Ibaraki 305-0006, Japan. ${ }^{2}$ International Research Institute of Disaster Science, Tohoku University, 468-1 Aza-Aoba, Aramaki, Aoba-ku, Sendai 980-0845, Japan. ${ }^{3}$ Graduate School of Science, Tohoku University, 6-6 Aza-Aoba, Aramaki, Aoba-ku, Sendai 980-8578, Japan. ${ }^{4}$ Geological Survey of Japan, National Institute of Advanced Industrial Science and Technology, AIST, Tsukuba Central 7, Higashi-1-1-1, Tsukuba, Ibaraki 305-8567, Japan.

Published online: 09 November 2021

\section{Reference}

Maeda S, Toda S, Matsuzawa T, Otsubo M, Matsumoto T (2021) Influence of crustal lithology and the thermal state on microseismicity in the Wakayama region, southern Honshu, Japan. Earth Planets Space 73:173. https:// doi.org/10.1186/s40623-021-01503-3

\section{Publisher's Note}

Springer Nature remains neutral with regard to jurisdictional claims in published maps and institutional affiliations. 